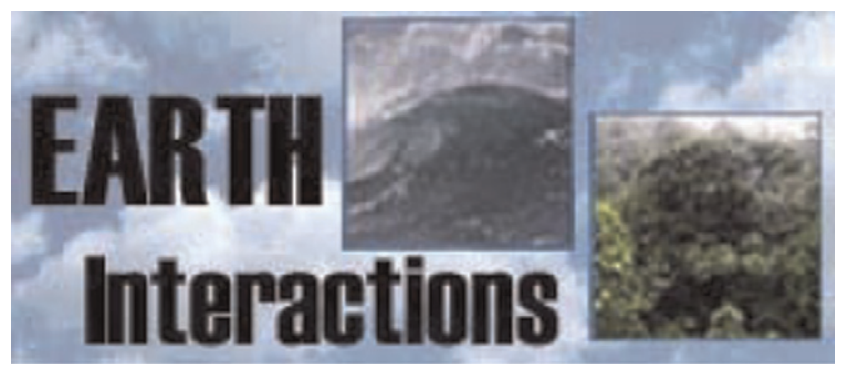

Copyright $\odot$ 2012, Paper 16-012; 36470 words, 7 Figures, 0 Animations, 0 Tables. http://EarthInteractions.org

\title{
Evaluation of a Dynamic Agroecosystem Model (Agro-IBIS) for Soybean in Southern Brazil
}

\section{Geovane Webler and Débora Regina Roberti*}

Physics Department, Federal University of Santa Maria, Santa Maria, Brazil

\section{Santiago Vianna Cuadra}

Department of Atmospheric Sciences, Federal Center of Technological Education Celso Suckow da Fonseca (CEFET/RJ), Rio de Janeiro, Brazil

\section{Virnei Silva Moreira}

Federal University of Pampa, Itaqui, Brazil

\section{Marcos Heil Costa}

Department of Agricultural Engineering, Federal University of Viçosa, Viçosa, Brazil

Received 21 March 2012; accepted 22 June 2012

\begin{abstract}
With the growing demands for food and biofuel, new technologies and crop management systems are being used to increase productivity and minimize land-use impacts. In this context, estimates of productivity and the impacts of agriculture management practices are becoming increasingly important. Numerical models that describe the soil-surface-atmosphere interactions for natural and agricultural ecosystems are important tools to explore the impacts of these agronomical technologies and their environmental impacts.
\end{abstract}

* Corresponding author address: Débora Regina Roberti, Universidade Federal de Santa Maria Fisica, Santa Maria, RS 97105900, Brazil.

E-mail address: debora@ufsm.br 
Earth Interactions - Volume 16 (2012) • Paper No. 12 • Page 2

However, these models need to be validated by considering the different soil and environmental conditions before they can be widely applied. The processbased terrestrial agricultural version of the Integrated Biosphere Simulator (IBIS) model (Agro-IBIS) has only been calibrated and validated for North American sites. Here, the authors validate the Agro-IBIS results for an experimental soybean site in southern Brazil. At this site, soybean was grown under two different management systems: no tillage (NT) and conventional tillage (CT). The model results were evaluated against micrometeorological, soil condition, and biomass observations made during the soybean growing season. The leaf area index (LAI) was underestimated, approaching the values obtained in the CT crop system, with higher error in the leaf senescence period. The model shows higher skill for daily averages and the diurnal cycle of the energy balance components in the period of high LAI. The soil temperature and moisture were robustly simulated, although the latter is best correlated with the observations made at the CT field. The ecosystem respiration is highly underestimated, causing an overestimation of the cumulative net ecosystem exchange (NEE), particularly at the end of the crop cycle.

KEYWORDS: Agro-IBIS; Soybean (Glycine max); Energy flux; Carbon flux

\section{Introduction}

The environmental impacts of agriculture systems have been extensively discussed by scientists and decision makers (e.g., Solomon et al. 2007). However, there is no consensus regarding the net contribution of agricultural areas to the net carbon exchange between the land surface and the atmosphere. Recent studies present different conclusions about the role of agroecosystems as a carbon source or sink (Verma et al. 2005; Hollinger et al. 2005), generating further discussion around this theme (Dobermann et al. 2006; Hollinger et al. 2006). Field measurements using eddy covariance techniques have been used to quantify the exchange of carbon, energy, water, and, more recently, methane between agroecosystems and the atmosphere (McDermitt et al. 2011). However, these measurements have local representation, and alternative methods are needed to regionalize these fluxes.

Numerical models that describe the land surface-atmosphere have become an important tool for the regional to global quantification of surface energy and carbon fluxes (e.g., Anderson-Teixeira et al. 2012). In recent years, several land surface models (LSMs) have incorporated different agroecosystems in addition to the traditional representation of natural ecosystems. For example, Hanan et al. (Hanan et al. 2005) adapted the Simple Biosphere Model (SiB2; Sellers et al. 1996) to simulate the wheat ecosystem, and Lokupitiya et al. (Lokupitiya et al. 2009) developed the Sibcrop, which incorporates the representation of soybean, maize, and wheat (Triticum aestivum L.). Another example is the agricultural version of the Integrated Biosphere Simulator (IBIS) model (Agro-IBIS), which is built around the IBIS modeling framework (Foley et al. 1996; Kucharik et al. 2000). Agro-IBIS includes the representation of maize, soybean, wheat (Kucharik 2003; Kucharik and Brye 2003; Kucharik and Twine 2007), Miscanthus giganteus (Vanloocke et al. 2010), and sugarcane (Cuadra et al. 2012).

Field measurements of carbon, water, and energy fluxes in agroecosystems, as well as products derived from satellites, have been used for the development and validation of these LSMs (e.g., Suyker et al. 2005; Kucharik and Twine 2007). 
Generally, these models are calibrated for specific sites and, when applied to different regions, simulations need to be revalidated because changes in soil conditions, climate, and characteristics of crop varieties may significantly impact the land surface fluxes. In southern Brazil, a long-term agronomical experiment is being conducted to evaluate two different soil management systems, no tillage (NT) and conventional tillage (CT), in relation to the soil-surface-atmosphere energy, water, and $\mathrm{CO}_{2}$ fluxes. Studies have shown that these different management systems may significantly impact the carbon and energy balance (e.g., Gupta et al. 1983; Kucharik and Twine 2007).

The objective of this study is to validate the land surface model Agro-IBIS, originally calibrated for North American conditions (Kucharik and Twine 2007) against micrometeorological observations made over two soybean management cropping systems in southern Brazil. Soybean is the main crop cultivated in Brazil, covering 23.6 million ha in the 2009/10 growing season (EMBRAPA 2011), and Brazil is the second largest producer of soybean in the world (producing approximately $27 \%$ of the global total). Initial soybean crops in Brazil typically used the CT cropping system, characterized by the annual use of plow. By the 1990s, most of the crops were converted to the NT system, which consists of plant cultivation without plowing or tilling and not removing mulch or straw from the soil surface. However, Agro-IBIS does not consider the impacts of crop residue management in the simulation of water and energy fluxes. By comparing the Agro-IBIS results against the micrometeorological observations in southern Brazil, we intend to answer the following questions: (i) Can a model calibrated for the North American conditions represent consistently the soybean crop in Brazil? (ii) Is the representation of mulching in the model necessary to represent the differences between CT and NT cultivation systems? (iii) What biophysical processes are satisfactorily represented? (iv) What are the impacts of the nonrepresentation of crop residue management in the simulation of mass and energy fluxes during the various stages of plant development?

\section{Materials and methods}

\section{1. Study site}

The study area is located at the Research and Experimental Foundation Center

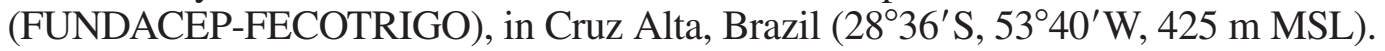
The native vegetation included Araucaria open forest and natural rangeland formed by grasses, predominantly Paspalum notatum Fluegge. In the 1950s, the area was deforested and converted to commercial agriculture with a wheat/soybean rotation under a conventional tillage system. In 1985, an experiment was started with the objective of comparing NT against CT. The experimental setup consists of an array of $40 \mathrm{~m} \times 60 \mathrm{~m}$ plots arranged in pairs. Experiments with different crops are conducted in each pair of plots, one with the NT system and the other with the CT system. These experiments are part of a large agricultural experimental area, with more than 200 ha, maintaining several paired NT/CT plots. Additional details about the site are given by Moreira et al. (Moreira et al. 2012, manuscript submitted to J. Agric. Water Manage.).

The micrometeorological observations collected during the soybean growing season in the 2009/10 summer are used to evaluate the Agro-IBIS. In this region, soybean is usually planted in November; however, due to excessive rainfall in 


\section{Earth Interactions • Volume 16 (2012) • Paper No. 12 • Page 4}

2009, the planting was delayed, and most of planting occurred on 14 December in the experimental area and in the surrounding region. The cultivar planted was Fundacep 53RR, whose main characteristic is early maturation. Physiological maturity was reached on 13 April 2010. The soybean growth stages were determined following the phenological scale proposed by Fehr and Caviness (Fehr and Caviness 1977). A large amount of rainfall in the two weeks after the soybean reached physiological maturity delayed the harvest until 28 April.

The latent and sensible heat fluxes and $\mathrm{CO}_{2}$ flux were estimated by the eddy covariance technique, and the sensors were installed over both tillage systems at a 2.5-m height. The soil water content was estimated (ranging from 0 to $1 \mathrm{~m}^{3} \mathrm{~m}^{-3}$ ) in the $0-0.20-\mathrm{m}$ and $0.20-0.50-\mathrm{m}$ layers under both NT and CT systems. The soil heat flux and soil temperature were measured at a 0.02-m depth in the soil, and the net radiation was measured at $2.5-\mathrm{m}$ height only in the NT system. Details about the instrumentation, experiment design, and footprint are reported in Moreira et al. (Moreira et al. 2012, manuscript submitted to J. Agric. Water Manage.).

Turbulent fluxes were corrected for inadequate sensor frequency response following standard methods in addition to despiking, coordinate rotation, and air density corrections (Webb et al. 1980; Baldocchi et al. 1988; Wyngaard 1990; Aubinet et al. 2000). Approximately $400 \mathrm{~m}$ from the eddy covariance towers, there is an automatic weather station (MAWS301) that measures the atmospheric variables used to force the simulation (continuous measurements since 1974). These observations were also used to describe the atmospheric conditions during the period analyzed and the climate classification of the Cruz Alta region.

The climate in Cruz Alta is classified as Cfa (Köppen classification) subtropical humid, with an average annual rainfall of $1755 \mathrm{~mm}$ evenly distributed throughout the year. The average annual temperature is $18.7^{\circ} \mathrm{C}$, with average minimum temperatures of $8.6^{\circ} \mathrm{C}$ in July (austral winter) and a maximum average of $30.0^{\circ} \mathrm{C}$ in January (austral summer). The climatological rainfall from December to April (typical soybean growing season) is $695 \mathrm{~mm}$, and for the 2009/10 growing season (experimental period) the accumulated precipitation was $758 \mathrm{~mm}$. Although the total precipitation during the 2009/10 growing season was close to the average, the rainfall distribution during the season was irregular (Figure 1). The January and March 2010 monthly precipitation deviate $72 \%$ above and $44 \%$ below the climatology, respectively. During the growth season, there were two significant dry periods (Figure 1). The first occurred between 73 and 100 days after planting (DAP), with $6.6 \mathrm{~mm}$ accumulated; the second covered the period between 102 and 130 DAP, with $9.8 \mathrm{~mm}$ accumulated.

\subsection{Model description}

Agro-IBIS includes 12 natural and 5 crop (soybean, maize, wheat, Miscanthus $x$. giganteus, and sugarcane) plant functional types (Kucharik and Brye 2003; Vanloocke et al. 2010; Cuadra et al. 2012). The model represents land surface processes related to energy, water, carbon, and momentum exchanges among the soil, vegetation (canopy and root system), and atmosphere. The model simulates the canopy physiology (photosynthesis and stomatal conductance), phenology, vegetation dynamics (carbon allocation and competition between plants), and 


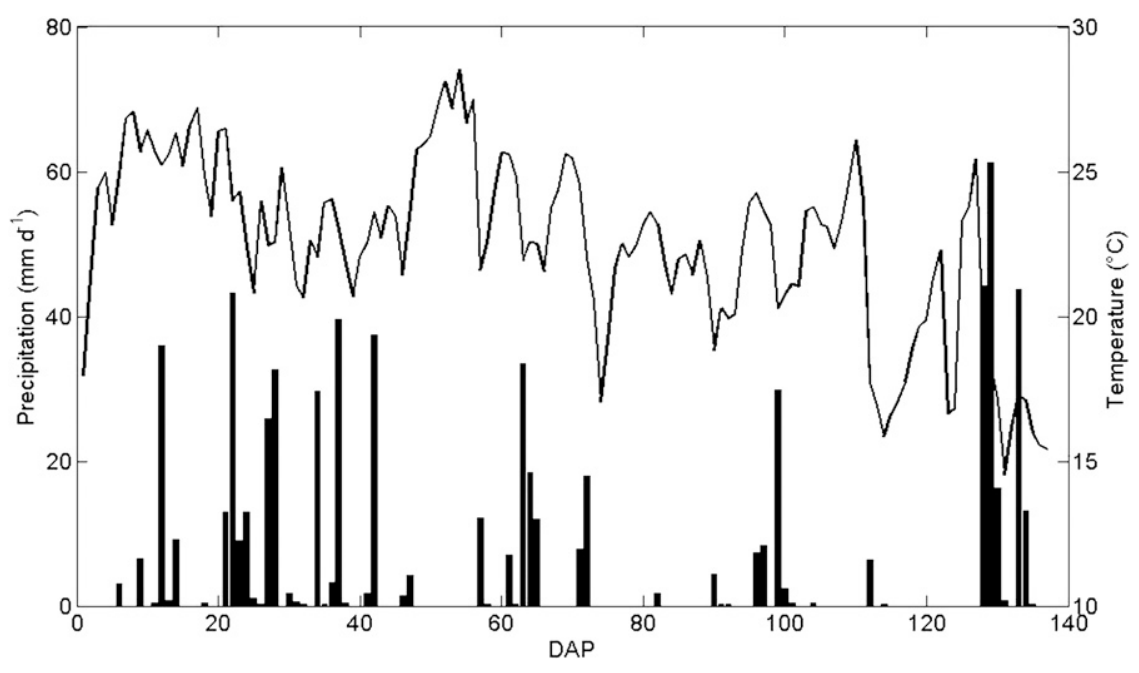

Figure 1. Daily average air temperature (line) and cumulative daily rainfall (bars) during the soybean growing season. The time scale is in DAP.

carbon balance (net primary production, carbon allocation, soil carbon, and organic matter decomposition; Foley et al. 1996; Kucharik et al. 2000). This approach allows coupling of the ecological, biophysical, and physiological processes that occur on different time scales. The model output includes crop productivity, dry matter production (leaves, stems, roots, and grains; $\mathrm{kg} \mathrm{C} \mathrm{m}^{-2}$ ), leaf area index (LAI; $\mathrm{m}^{-2} \mathrm{~m}^{-2}$ ), evapotranspiration $\left(\mathrm{mm}\right.$ day $\left.{ }^{-1}\right)$, and carbon flux $\left(\mu \mathrm{mol} \mathrm{CO}_{2}\right.$ $\mathrm{m}^{-2} \mathrm{~s}^{-1}$ ) (Kucharik and Brye 2003) on a daily basis.

In Agro-IBIS, the exchange of water vapor (evapotranspiration) and carbon (photosynthesis) between the vegetation and the atmosphere are controlled by stomatal and aerodynamic conductances. The Farquhar-Ball-Collatz equations are used to represent the photosynthesis and stomatal conductance (Farquhar et al. 1980; Farquhar and Sharkey 1982; Ball et al. 1986; Collatz et al. 1991). In these formulations, photosynthesis is a function of absorbed light, leaf temperature, $\mathrm{CO}_{2}$ concentration in the leaf, and the capacity of Rubisco (enzyme). Stomatal conductance is a function of the photosynthetic rate and the $\mathrm{CO}_{2}$ and water vapor concentrations (Foley et al. 1996).

The LAI is updated daily by the product between the carbon accumulated in the leaf pool and the specific leaf area. The fraction of carbon allocated to the different tissues (leaf, stem, root, and grain) varies with the crop phenological stages (emergence, grain fill, and senescence) governed by the accumulated growing degree days (GDD). Although Agro-IBIS considers the deposition of aboveground crop residue over the surface in the carbon cycle, the residue layer does not affect surface energy fluxes. Thus, the model does not simulate the effects of NT systems on water and energy balances, using a representation similar to CT.

Agro-IBIS was integrated with a 60-min time step, being forced with meteorological data (incident solar radiation, precipitation, air temperature, wind speed, relative humidity, and atmospheric pressure) obtained from an automatic weather station (MAWS301). The simulation was initialized in 1985 using a numerical 


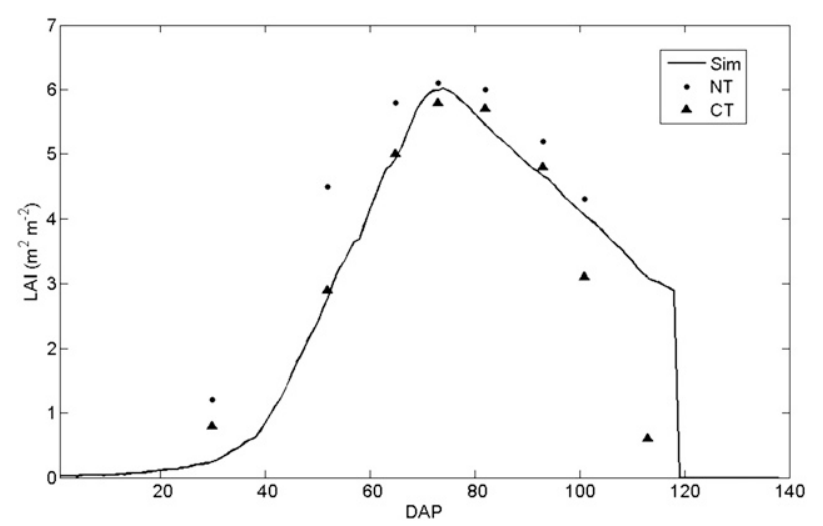

Figure 2. Simulated and observed LAI in the two management systems: NT and CT.

acceleration procedure (Kucharik et al. 2000), allowing the model to adjust the soil carbon pools to a representative equilibrium state. Soybean specific parameters were kept similar as described by Kucharik and Twine (Kucharik and Twine 2007, their Table 1). Planting dates were prescribed according to actual site management (see section 2.1), and soil physical properties were assigned based on local soil texture measurements ( $24 \%$ of silt, $52 \%$ of clay, and $24 \%$ of sand), with a total soil depth of $2.5 \mathrm{~m}$. Additionally, $\mathrm{GDD}_{10}$ was set to $1760^{\circ} \mathrm{C}$-days to match the observed $\mathrm{GDD}_{10}$ accumulated between the assigned planting and harvest dates. As AgroIBIS does not represent the crop residue management and hence does not characterize the no-tillage system, we have performed only one simulation, which is compared with both managements systems.

\section{Results}

\subsection{LAl}

One of the most important simulated variables in crop simulations is the leaf area index, which directly affects the energy, water, and carbon fluxes. Figure 2 shows the observed LAI for the NT and CT and the simulated LAI by Agro-IBIS. LAI is underestimated in the beginning of the growing season and overestimated during senescence, where it is closer to observations in the middle of the season. Simulations are closer to the CT observations, which had lower LAI values. The model underestimates the LAI by $\sim 50 \%$ in the first experimental measurement (28 DAP). Apparently, the model allocated too little carbon to the leaves during emergence. Bias was reduced during the reproductive phase (50-90 DAP), with an average underestimation of $17 \%$ (10\%) compared with the NT (CT). The end of the growing season (from the 100th DAP) is characterized by an intense leaf senescence, and the model clearly does not follow the observed LAI decrease.

This LAI overestimation during the senescence phase is a systematic bias in crop simulations with Agro-IBIS. For example, Kucharik and Twine (Kucharik and Twine 2007) and Maayar and Sonnentag (Maayar and Sonnentag 2009) also reported model deficiencies in simulating the LAI decline during crop senescence 
Earth Interactions - Volume 16 (2012) • Paper No. 12 • Page 7

(for soybean, maize, and wheat). Agro-IBIS uses empirical equations and coefficients to control the amount of carbon allocated to the different plant tissues, which change according to the three crop growth stages. The last stage includes the period of grain filling and physiological maturity. Although this last stage was initially consistently simulated by model, with the inflection of the LAI curve, the LAI decline is clearly underestimated at the end of the senescence stage. Another source of model uncertainty is the use of a constant specific leaf area (SLA; $\mathrm{m}^{2} \mathrm{~kg}^{-1}$ ) through the entire crop cycle, while SLA is related to plant development stage (Yin et al. 2000). Other factors may also affect the LAI decline more directly, like soil moisture.

\subsection{Energy balance}

The sensible $(H)$ and latent (LE) heat fluxes for both tillage systems (CT and NT) presented similar results, with daily differences lower than $2 \%$. Because of these small $H$ and LE differences and the absence of soil heat flux $(G)$ and net radiation $(\mathrm{Rn})$ observations over the CT plot, the evaluation of the Agro-IBIS energy balance presented considers only the observations made over the NT plot. The relationship between turbulent fluxes and energy balance (i.e., $H+\mathrm{LE}$ and $\mathrm{Rn}-G$ ) for the experimental data shows an average daily surface imbalance of approximately $5 \%$. Figures 3a-d shows the simulated and observed (CT) daily LE, $H, G$, and Rn for the soybean growing season. In the first 20 DAP, Rn (Figure 3d) and consequently LE (Figure 3a) were overestimated by the model. The simulated daily $H$ and $G$ fluxes (Figures 3b,c) have smaller deviations during this initial stage of crop development. From the 30th DAP, when the canopy completely covers the soil, all components of simulated energy balance show magnitude and daily fluctuations $\left(R^{2}\right.$ ranging from 0.57 to 0.86 ) similar to the observations. Between 45 and 105 DAP (observed LAI $>2.0 \mathrm{~m}^{2} \mathrm{~m}^{-2}$ ), both model and observations show that soybean had high photosynthetic activity and evapotranspiration (Figure 3a). Moreover, because the ground surface is almost completely shaded by the canopy, there was low radiation reaching the ground; consequently, $G$ tends to be smaller, a pattern that was correctly simulated. At the end of the crop cycle, during leaf senescence period, the simulated Rn and LE systematically deviate from the observations, being driven by the incorrect simulation of the LAI decrease (Figure 2).

The analysis of the average diurnal cycle of the energy balance components (Figures 4a-d) was separated in two periods: emergence (12-24 DAP) and maximum LAI (72-84 DAP). For both periods, LE (Figure 4a) was closely simulated during the morning period and overestimated in the afternoon. During emergence (gray lines and symbols), $H$ (Figure $4 \mathrm{~b}$ ) and $G$ (Figure 4c) are underestimated and overestimated by the model, respectively. During the period of high LAI (black lines and symbols), the energy balance components are better simulated, although the overestimation in the afternoon persists. Throughout the day $G$ (Figure 4c) was highly overestimated, even in the hours when $\mathrm{Rn}$ is closely simulated.

\subsection{Soil temperature and moisture}

Soil temperature was measured only in the NT system. As described earlier, in this system, the soil is covered by the residues after harvest, which tends to result in 
Earth Interactions - Volume 16 (2012) • Paper No. 12 • Page 8
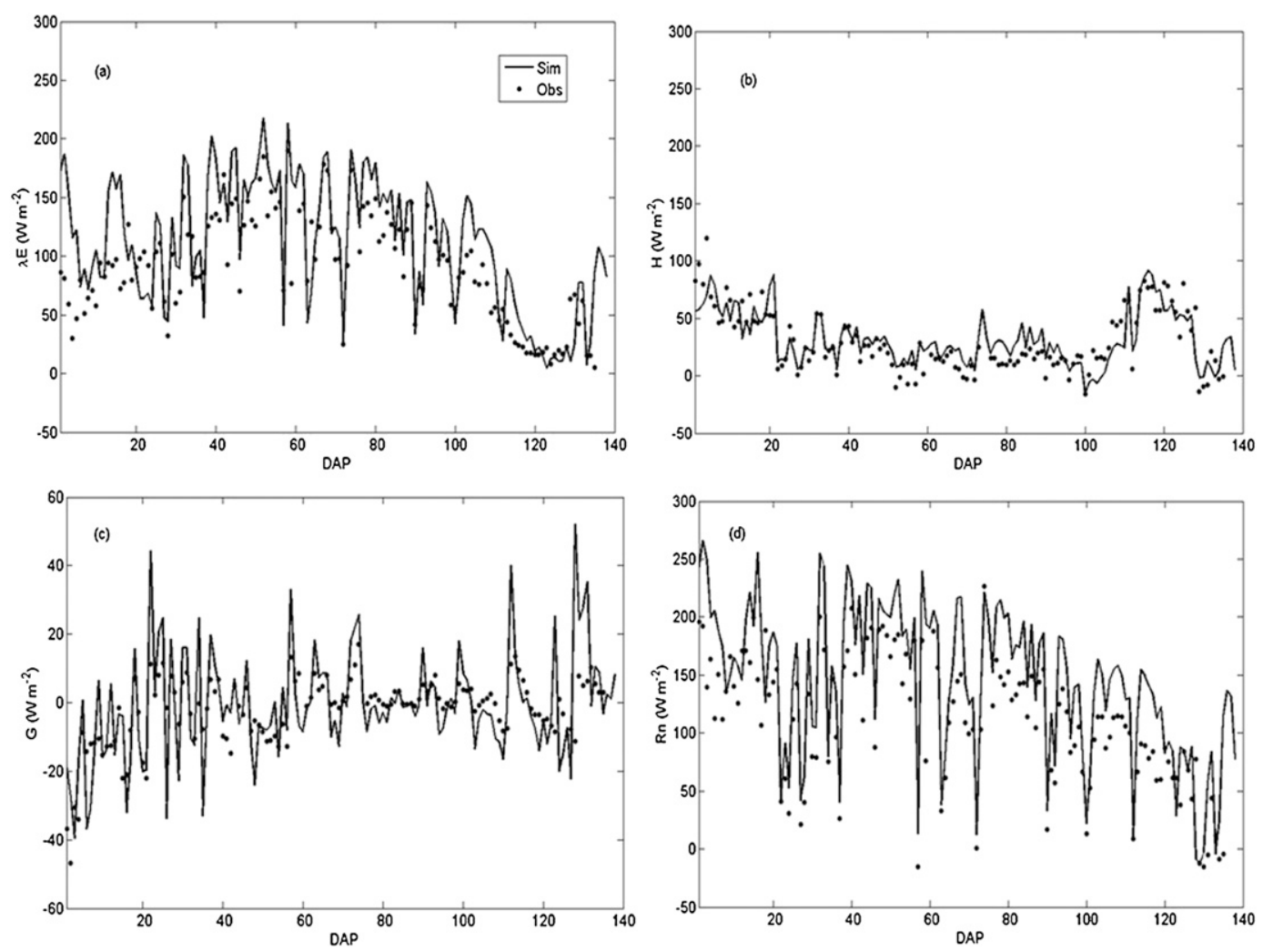

Figure 3. Simulated and observed daily average energy balance components along the soybean growing season: (a) latent heat flux LE, (b) sensible heat flux $H$, (c) soil heat flux $G$, and (d) net radiation Rn.

a lower soil temperature compared with the CT management system (Moreira et al. 2012, manuscript submitted to J. Agric. Water Manage.). The soil temperature (0.02-m depth) is overestimated by the model (Figure 5a) at the beginning (until 20 DAP) of the growing season, when the LAI $<1 \mathrm{~m}^{2} \mathrm{~m}^{-2}$. Because the soil temperature is influenced by the presence of crop residues, the overestimation of the soil temperature by the model at the beginning and at end of the soybean growing season can be partially justified by the presence of crop residues on the ground. The surface covered by crop residues generally has a higher reflectance than bare soil, reducing the absorbed radiation and soil temperature. Because Agro-IBIS does not include crop residue parameterization, the model overestimates $\mathrm{Rn}$ and soil temperature when the soil surface is uncovered by the crop. Kucharik and Twine (Kucharik and Twine 2007) also reported an overestimation of the soil temperature by $4^{\circ}-10^{\circ} \mathrm{C}$ in the absence of vegetation cover. In this work the soil temperature bias reached, at the most, $5^{\circ} \mathrm{C}$ at the beginning and end of the growing season, when the canopy cover was low.

When LAI increases, solar radiation is intercepted by the leaves and the crop residue's effect on the soil temperature decreases, reducing the model bias (Figure 5b). When the crop covers the surface, between 30 and 110 DAP 

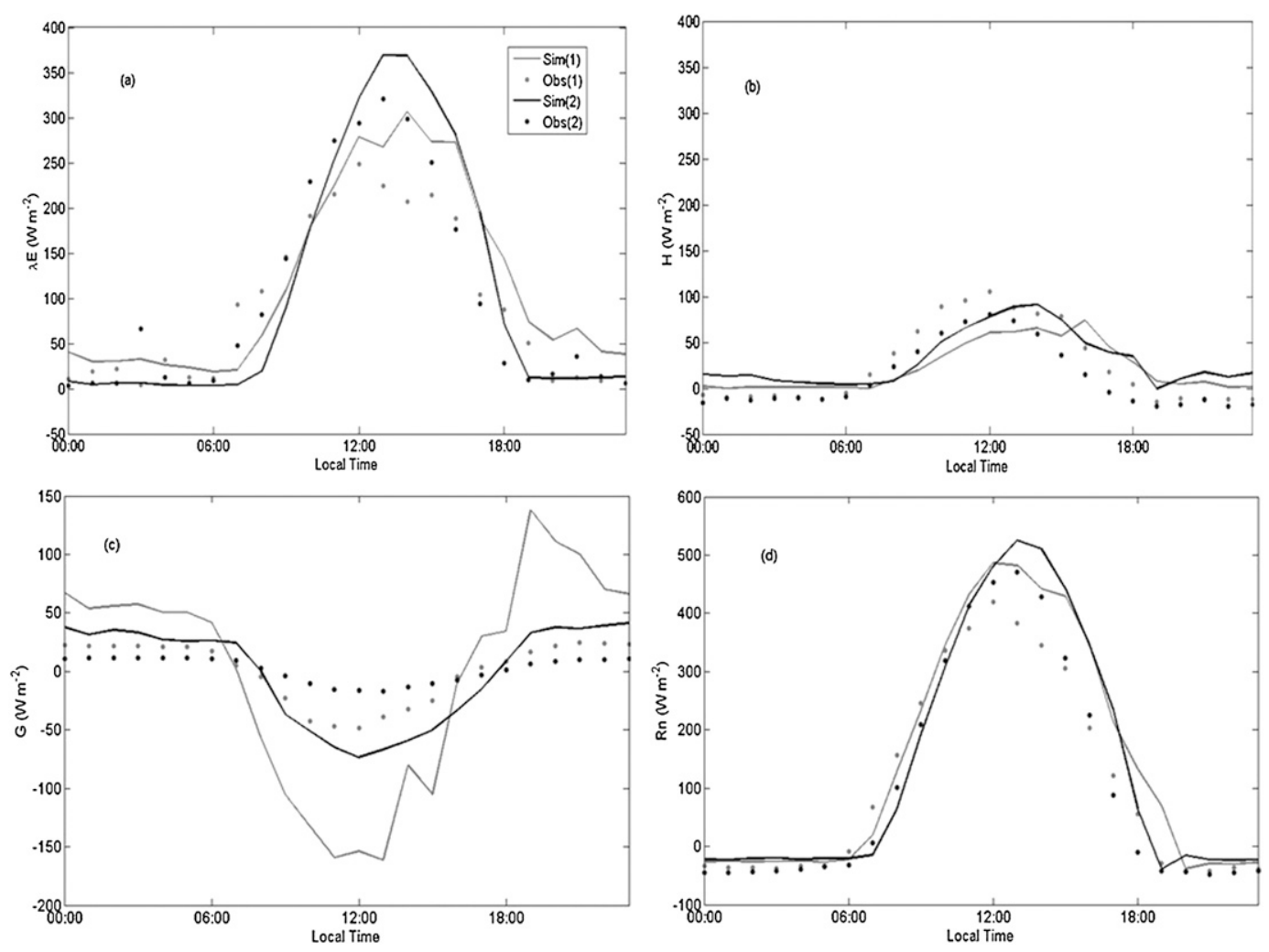

Figure 4. Simulated (Sim) and observed (Obs) average diurnal cycle of the energy balance components: (a) latent heat flux LE, (b) sensible heat flux $H$, (c) soil heat flux $G$, and (d) net radiation Rn. Period 1 is the emergence period (1224 DAP) and period 2 is the period with maximum LAI (72-84 DAP).

$\left(\right.$ LAI $>1 \mathrm{~m}^{2} \mathrm{~m}^{-2}$ ), the model simulates the soil temperature amplitude and fluctuations close to the observations (RMSE equal to $2.09^{\circ} \mathrm{C}$ ).

The experimental measurements of soil volumetric water content were made in the $0-0.2-\mathrm{m}$ and $0.2-0.5-\mathrm{m}$ layers in both CT and NT systems. The volumetric water content for the $0-0.5-\mathrm{m}$ layer was calculated by the weighted average of the $0-0.2-\mathrm{m}$ and $0.2-0.5-\mathrm{m}$ layers (Figure 6a). While the first layer presents similar water content values between CT and NT systems, the water content is systematically higher under the NT system in the 0.2-0.5-m layer (Figure 6b). Agro-IBIS simulated a similar magnitude and fluctuations of daily average soil volumetric water content compared with the two management systems. The highest deviations from the observations occur after 100 DAP, when the model overestimates LAI and consequently the LE and soil water uptake.

\section{4. $\mathrm{CO}_{2}$ flux}

Figure 7a presents the simulated and observed daily net ecosystem exchange (NEE) averages. Experimentally, the CT and NT systems have similar daily NEE variability, although NEE was systematically lower in the NT system (higher 

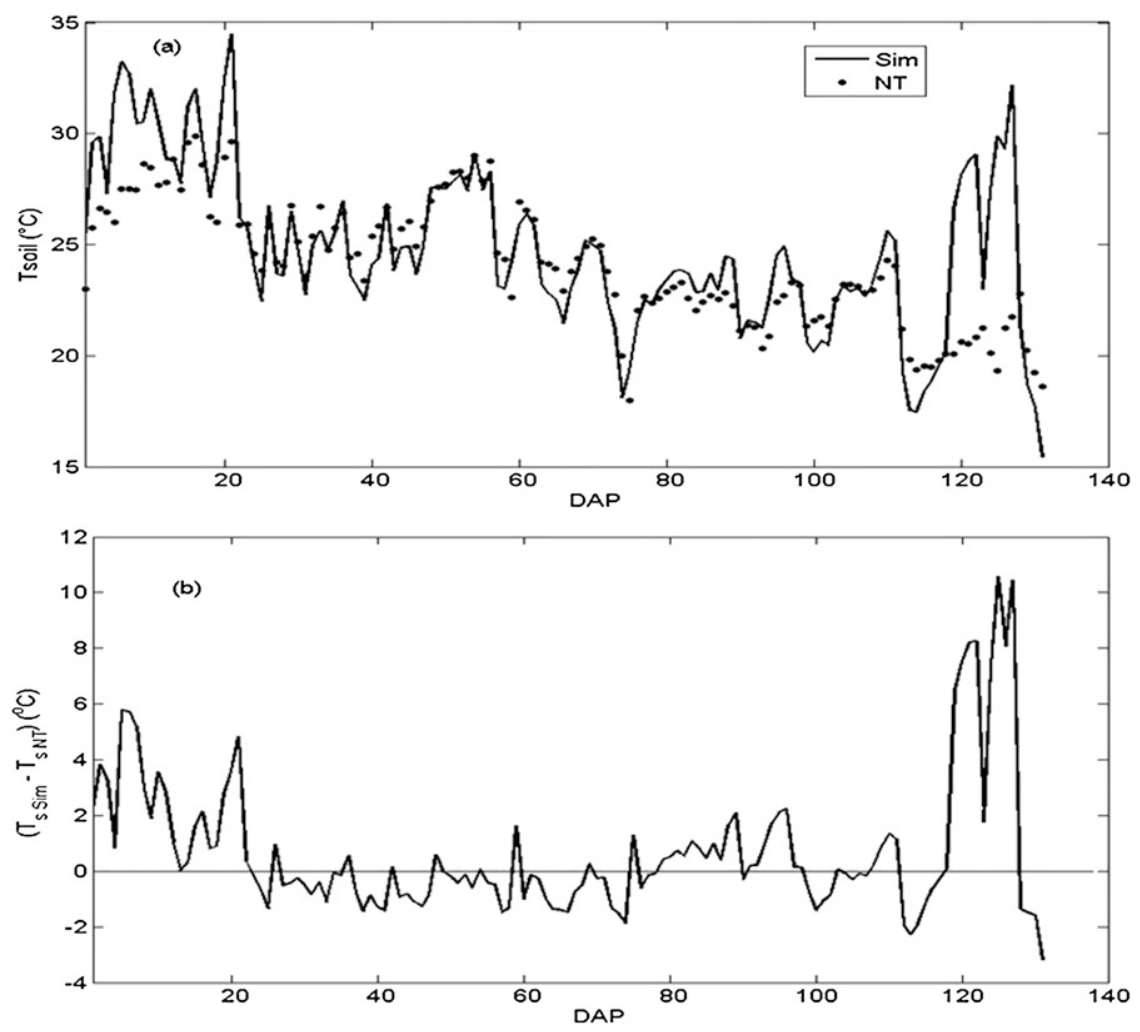

Figure 5. Soil temperature: (a) simulated and observed daily average and (b) differences between simulated ( $\left.T_{s \text { sim }}\right)$ and experimental $\left(T_{s} \mathrm{NT}_{\mathrm{N}}\right)$ daily averages.

carbon absorption or less emission). The simulations follow the observations from sowing to 35 DAP, after which the model overestimated the daily NEE compared with the two experimental management systems (Figure 7a).

For the diurnal NEE, average from 0800 to 1800 local civil time (LCT), the model represents similar magnitudes and fluctuations during most of the growing season (Figure 7b). During the final crop stage, leaf senescence, the observations show that the ecosystem becomes a source of carbon. Although the model simulates a NEE decrease during this last stage, it still simulates considerable carbon absorption during the senescence period.

The net ecosystem exchange can be represented by the sum of ecosystem respiration (Re) and gross primary production (GPP),

$$
\mathrm{NEE}=\mathrm{GPP}+\mathrm{Re} .
$$

During the night GPP is null and NEE is equal to Re. By comparing the daily (Figure 7a) and diurnal (Figure 7b) NEEs, we conclude that the model underestimates Re and overestimates GPP during most of the growth period stage (until $\sim 90$ DAP), as the model presents similar results for the diurnal NEE and overestimates the daily NEE. Along the growing season, Re underestimation was 
Earth Interactions - Volume 16 (2012) • Paper No. 12 • Page 11
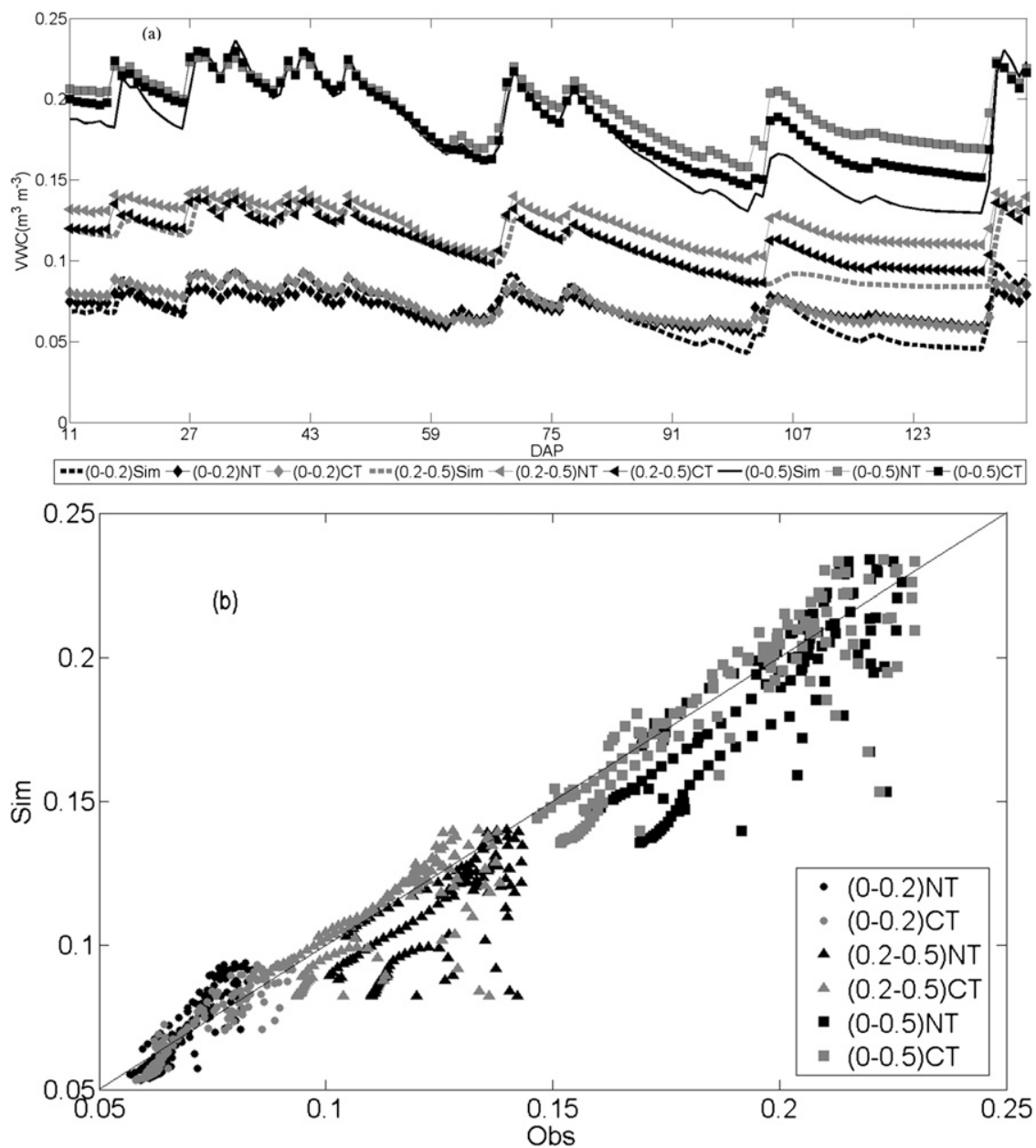

Figure 6. (a) Simulated and observed daily average of soil volumetric water content in the 0-0.2-, 0.2-0.5-, and 0-0.5-m layers. (b) Scatterplot between simulated and experimental soil volumetric water content data for the 0-0.2-, $0.2-0.5-$, and $0-0.5-\mathrm{m}$ layers.

estimated to vary between 3 and $5 \mathrm{~g} \mathrm{C} \mathrm{m}^{-2}$ day $^{-1}$. The largest error in Re occurs during the period of maximum LAI, suggesting that Re underestimation is influenced by both heterotrophic and autotrophic respirations.

\section{Discussion and conclusions}

In general, Agro-IBIS represents the soybean growth and surface fluxes for the southern Brazil conditions consistently, despite using a calibration for North American conditions by Kucharik and Twine (Kucharik and Twine 2007). Only the model parameters related to the crop management were changed: for example, the sowing dates and maximum GDD required to reach physiological maturity. LAI was closely simulated during most of the crop development stages, except during emergence and senescence. The model fails mainly at the end of the growing 
Earth Interactions - Volume 16 (2012) • Paper No. 12 • Page 12
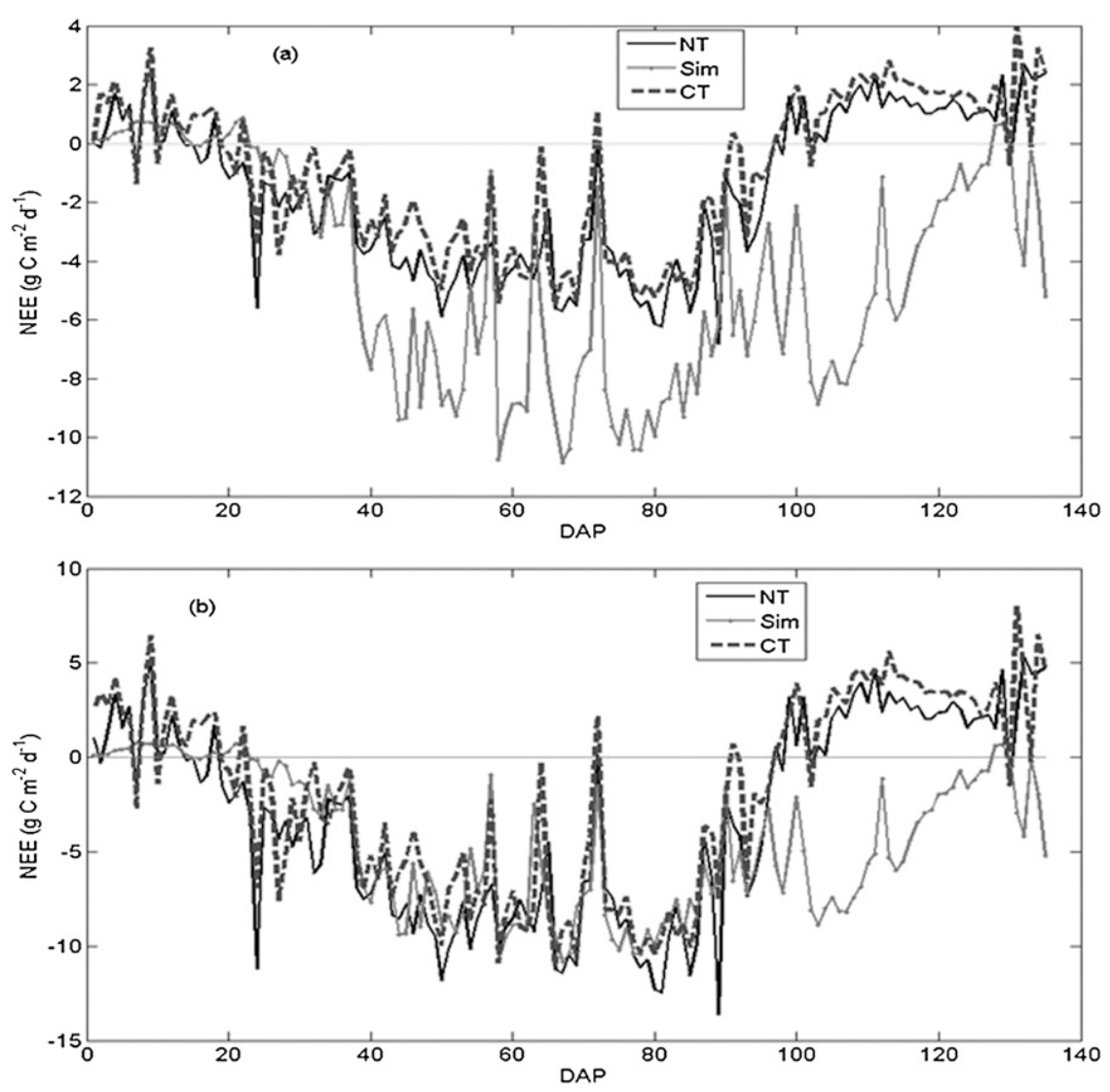

Figure 7. (a) Simulated and observed daily NEE average in the two management systems: NT and CT. (b) Simulated and observed daytime NEE average (0800-1800 LCT) in the two management systems (CT and NT).

season (from 100th DAP), where the observations indicate an intense leaf senescence, and the model clearly does not follow the observed LAI decrease. The latter seems to be a systematic problem in the LAI parameterization scheme, as this problem is also evident in several simulations presented previously (Kucharik and Twine 2007; Maayar and Sonnentag 2009).

The model's skill in simulating the daily energy balance components ( $\mathrm{Rn}, \mathrm{LE}, H$, and $G$ ) along the soybean growing season was tightly connected to the LAI simulation. Higher deviations were simulated during emergence and senescence, when the LAI bias was high, with the model converging to observations when the surface was covered by the canopy. The average diurnal cycle of the energy balance components for the emergence and maximum LAI periods was generally better simulated for the Rn and LE components; $G$ was highly overestimated throughout the day, even in the hours when Rn was well simulated.

The soil temperature $(0.02-\mathrm{m}$ depth) was closely simulated when vegetation covers the surface and was overestimated at the beginning of the growing season, when $G$ was highly overestimated. Kucharik and Twine (Kucharik and Twine 2007) also reported that near-surface soil temperatures $(0-0.1 \mathrm{~m})$ were overestimated in 
Earth Interactions - Volume 16 (2012) • Paper No. 12 • Page 13

the absence of vegetation cover. In both cases, the experimental observations were made over no-till management systems, and the soil heat flux and soil temperature were measured only in the NT system. Therefore, we reiterate the importance of including a crop residue parameterization to simulate soil temperature consistently in periods of low vegetation cover. We also show that the nonconsideration of an explicit crop residue parameterization resulted in a significant positive soil heat flux bias, affecting not only the simulation of the energy balance (as soil temperature bias) but also the simulated biogeochemical processes, such as soil organic matter decomposition.

Kucharik et al. (Kucharik et al. 2006) and Kucharik and Twine (Kucharik and Twine 2007) reported a significant overestimation of soil moisture for validations with IBIS/Agro-IBIS against observations made over natural and agroecosystems, respectively. In the present validation, Agro-IBIS simulated similar magnitudes and fluctuations of daily average soil volumetric water content compared with the two tillage systems.

The model overestimated the daily NEE average (average from 0000 to 2300 LCT) compared with the two experimental management systems during the active soybean growth stage. However, the model represents similar magnitudes and fluctuations of the diurnal NEE (average from 0800 to 1800 LCT). Therefore, we conclude that the model underestimated the ecosystem respiration. We estimated an ecosystem respiration underestimation of 3-5 $\mathrm{g} \mathrm{C} \mathrm{m}^{-2} \mathrm{day}^{-1}$, which is similar to that reported by Kucharik and Twine (Kucharik and Twine 2007), 2-4 $\mathrm{g} \mathrm{C} \mathrm{m}^{-2}$ day $^{-1}$. As suggested by Kucharik and Twine (Kucharik and Twine 2007), this underestimation is related to the heterotrophic and plant tissue respiration formulation. Our results give more confidence to this hypothesis, as the drivers of the model respiration equations (temperature and soil moisture) were closely simulated during the period, while the ecosystem respiration was highly underestimated.

The overall conclusion is that, with minor changes, the Agro-IBIS calibrated for the North American conditions can consistently represent the growth and development stages of soybean crops in southern Brazil. Most of changes needed are related to the crop phenological stages, which are governed by the accumulated growing degree days (GDD). Future integrations of model at global scale will impose the inclusion of explicit equations to account for the effects of different climate regimes. For example, the GDD to reach physiological maturity was estimated as $1760^{\circ} \mathrm{C}$-day for the Cruz Alta site and $1300^{\circ} \mathrm{C}$-day for the Nebraska AmeriFlux site (Kucharik and Twine 2007). However, major physiological related parameters, like $V_{\max }$ (maximum catalytic capacity of Rubisco for $\mathrm{CO}_{2}$ fixation) and the slope and intercept point of the conductance-photosynthesis relationship, which controls photosynthesis and transpiration, seems to be applicable at multiple sites.

The impact of nonrepresentation of crop residues in the Agro-IBIS, which characterizes the no-tillage system, significantly affects the representation and prediction of soil moisture and temperature during periods of low LAI cover. In the future, the surface residue layer may be included explicitly as an independent layer. The mulch layer may be considered as a layer that can intercept rainfall and radiation, store water and energy, and exchange energy and water with the soil surface and the atmospheric layer. 
Earth Interactions • Volume 16 (2012) • Paper No. 12 • Page 14

Acknowledgments. The authors wish to acknowledge the Brazilian agencies CNPq, CAPES, and FAPERGS for their financial support.

\section{References}

Anderson-Teixeira, K. J., P. K. Snyder, T. E. Twine, S. V. Cuadra, M. H. Costa, and E. H. DeLucia, 2012: Climate-regulation services of natural and agricultural ecoregions of the Americas. Nat. Climate Change, 2, 177-181.

Aubinet, M., and Coauthors, 2000: Estimates of the annual net carbon and water exchange of forests: The EUROFLUX methodology. Adv. Ecol. Res., 30, 113-175.

Baldocchi, D. D., B. B. Hicks, and T. P. Meyers, 1988: Measuring biosphere-atmosphere exchanges of biologically related gases with micrometeorological methods. Ecology, 69, 1331-1340.

Ball, J. T., I. E. Woodrow, and J. A. Berry, 1986: A model predicting stomatal conductance and its contribution to the control of photo-synthesis under different environmental conditions. Progress in Photosynthesis Research, J. Biggins, Ed., Vol. 4, Mar-tinus Nijhoff, 221-224.

Collatz, J. G., C. Grivet, and J. A. Berry, 1991: Physiological and environmental regulation of stomatal conductance, photosynthesis and transpiration: A model that includes a laminar boundary layer. Agric. For. Meteor., 53, 107-136.

Cuadra, S. V., and Coauthors, 2012: A biophysical model of sugarcane growth. GCB Bioenergy, 4, $36-48$.

Dobermann, A., J. M. Baker, and D. T. Walters, 2006: Comment on "Carbon budget of mature notill ecosystem in North Central Region of the United States”. Agric. For. Meteor., 136, 83-84.

EMBRAPA, cited 2011: Londrina: Embrapa soja (Soybeans: History). Brazilian Agricultural Research Corporation. [Available online at http://www.cnpso.embrapa.br/.]

Farquhar, G. D., and T. D. Sharkey, 1982: Stomatal conductance and photosynthesis. Annu. Rev. Plant Physiol., 33, 317-345.

- S. von Caemmerer, and J. A. Berry, 1980: A biochemical model of photosynthetic $\mathrm{CO}_{2}$ assimilation in leaves of $\mathrm{C}_{3}$ species. Planta, 149, 78-90.

Fehr, W. E., and C. E. Caviness, 1977: Stages of soybean development. Iowa State University of Science and Technology Cooperative Extension Service and Agriculture and Home Economics Experiment Station Special Rep 80, 11 pp.

Foley, J. A., I. C. Prentice, N. Ramankutti, S. Levis, D. Pollard, S. Stich, and A. Haxeltine, 1996: An integrated biosphere model of land surface processes, terrestrial carbon balance and vegetation dynamics. Global Biogeochem. Cycles, 10, 603-628.

Gupta, S. C., W. E. Larson, and D. R. Linden, 1983: Tillage and surface residue affects on soil upper boundary temperatures. Soil Sci. Soc. Amer. J., 47, 1212-1218.

Hanan, N. P., J. A. Berry, S. B. Verma, E. A. Walter-Shea, A. E. Suyker, G. G. Burba, and A. S. Denning, 2005: Testing a model of $\mathrm{CO}_{2}$, water and energy exchange in Great Plains tallgrass prairie and wheat ecosystems. Agric. For. Meteor., 131, 162-179.

Hollinger, S. E., C. J. Bernacchi, and T. P. Meyers, 2005: Carbon budget of mature no-till ecosystem in north central region of the United States. Agric. For. Meteor., 130, 59-69.

,$- \ldots$, and 2 2006: A reply to "Comment on 'Carbon budget of mature no-till ecosystem in north central region of the United States' by Dobermann et al." Agric. For. Meteor., 136, 85 .

Kucharik, C. J., 2003: Evaluation of a process-based agro-ecosystem model (Agro IBIS) across the U.S. Corn Belt: Simulations of the interannual variability in maize yield. Earth Interact., 7. [Available online at http://EarthInteractions.org.]

— tions for Wisconsin maize receiving varied amounts of nitrogen fertilizer. J. Environ. Qual., 32, 247-268. 


\section{Earth Interactions - Volume 16 (2012) • Paper No. 12 • Page 15}

— and T. E. Twine, 2007: Residue, respiration, and residuals: Evaluation of a dynamic agroecosystem model using eddy flux measurements and biometric data. Agric. For. Meteor., 146, 134-158.

—, J. A. Foley, C. Delire, V. A. Fisher, M. T. Coe, J. D. Lenters, C. Young-Molling, and N. Ramankutty, 2000: Testing the performance of a dynamic global ecosystem model: Water balance, carbon balance and vegetation structure. Global Biogeochem. Cycles, 14, 795-825.

- C. Barford, M. El Maayar, S. C. Wofsy, R. K. Monson, and D. D. Baldocchi, 2006: A multiyear evaluation of a dynamic global vegetation model at three AmeriFlux sites: Vegetation structure, phenology, soil temperature, and $\mathrm{CO}_{2}$ and $\mathrm{H}_{2} \mathrm{O}$ vapor exchange. Ecol. Modell., 196, 1-31.

Lokupitiya, E., and Coauthors, 2009: Incorporation of crop phenology in Simple Biosphere Model (SiBcrop) to improve land-atmosphere carbon exchanges from croplands. Biogeosciences, 6 , 969-986.

Maayar, M. E., and O. Sonnentag, 2009: Crop model validation and sensitivity to climate change scenarios. Climate Res., 39, 47-59.

McDermitt, D., and Coauthors, 2011: A new low-power, open-path instrument for measuring methane flux by eddy covariance. Appl. Phys., 102B, 391-405.

Sellers, P. J., and Coauthors, 1996: A revised land surface parameterization (SiB2) for atmospheric GCMs. Part I. Model formulation. J. Climate, 9, 676-705.

Solomon, S., D. Qin, M. Manning, M. Marquis, K. Averyt, M. M. B. Tignor, H. L. Miller Jr., and Z. Chen, Eds., 2007: Climate Change 2007: The Physical Science Basis. Cambridge University Press, 996 pp.

Suyker, A. E., S. B. Verma, G. G. Burba, and T. J. Arkebauer, 2005: Gross primary production and ecosystem respiration of irrigated maize and irrigated soybean during a growing season. Agric. For. Meteor., 131, 180-190.

Vanloocke, A., C. J. Bernacchi, and T. E. Twine, 2010: The impacts of Miscanthus x giganteus production on the Midwest US hydrologic cycle. Glob. Change Biol. Bioenergy, 2, 180-191.

Verma, S. B., and Coauthors, 2005: Annual carbon dioxide exchange in irrigated and rainfed maizebased agroecosystems. Agric. For. Meteor., 131, 77-96.

Webb, E. K., G. I. Pearman, and R. Leuning, 1980: Correction of flux measurements for density effects due to heat and water vapour transfer. Quart. J. Roy. Meteor. Soc., 106, 85-100.

Wyngaard, J. C., 1990: Scalar fluxes in the planetary boundary layer-Theory, modeling and measurement. Bound.-Layer Meteor., 50, 49-75.

Yin, X., A. H. C. M. Schapendonk, M. J. Kropff, M. Van Oijen, and P. S. Bindraban, 2000: A generic equation for nitrogen-limited leaf area index and its application in crop growth models for predicting leaf senescence. Ann. Bot., 85, 579-585.

Earth Interactions is published jointly by the American Meteorological Society, the American Geophysical Union, and the Association of American Geographers. Permission to use figures, tables, and brief excerpts from this journal in scientific and educational works is hereby granted provided that the source is acknowledged. Any use of material in this journal that is determined to be "fair use" under Section 107 or that satisfies the conditions specified in Section 108 of the U.S. Copyright Law (17 USC, as revised by P.IL. 94553 ) does not require the publishers' permission. For permission for any other from of copying, contact one of the copublishing societies. 